\title{
Effect of High $\mathrm{NH}_{3}$ Input Partial Pressure on Hydride Vapor Phase Epitaxy of InN Using Nitrided (0001) Sapphire Substrates
}

Rie Togashi, Sho Yamamoto, Fredrik K. Karlsson, Hisashi Murakami, Yoshinao Kumagai,

Per-Olof Holtz and Akinori Koukitu

\section{Linköping University Post Print}

\section{Tweet}

N.B.: When citing this work, cite the original article.

Original Publication:

Rie Togashi, Sho Yamamoto, Fredrik K. Karlsson, Hisashi Murakami, Yoshinao Kumagai, Per-Olof Holtz and Akinori Koukitu, Effect of High $\mathrm{NH}_{3}$ Input Partial Pressure on Hydride Vapor Phase Epitaxy of InN Using Nitrided (0001) Sapphire Substrates, 2013, Japanese Journal of Applied Physics, (52), 8.

http://dx.doi.org/10.7567/JJAP.52.08JD05

Copyright: Japan Society of Applied Physics http://www.jsap.or.jp/

Postprint available at: Linköping University Electronic Press http://urn.kb.se/resolve?urn=urn:nbn:se:liu:diva-98149 
Effect of High $\mathrm{NH}_{3}$ Input Partial Pressure on Hydride Vapor Phase Epitaxy of InN Using Nitrided (0001) Sapphire Substrates

Rie Togashi ${ }^{1 *}$, Sho Yamamoto ${ }^{1}$, K. Fredrik Karlsson ${ }^{2}$, Hisashi Murakami ${ }^{1}$, Yoshinao Kumagai $^{1}$, Per-Olof Holtz ${ }^{2}$, and Akinori Koukitu ${ }^{1}$

${ }^{1}$ Department of Applied Chemistry, Graduate School of Engineering, Tokyo University of Agriculture and Technology, Koganei, Tokyo 184-8588, Japan

${ }^{2}$ Department of Physics, Chemistry and Biology (IFM), Linköping University, S-581 83, Linköping, Sweden

The influence of the source gas supply sequence prior to growth and the $\mathrm{NH}_{3}$ input partial pressure $\left(\mathrm{P}^{\mathrm{o}}{ }_{\mathrm{NH}}\right)$ on the nucleation of $\mathrm{InN}$ islands during the initial stages of hydride vapor phase epitaxy on a nitrided (0001) sapphire substrate was investigated. The crystalline quality of the InN layer after subsequent lateral growth was also examined. When $\mathrm{NH}_{3}$ was flowed prior to growth, single-crystal hexagonal InN islands formed. When InN was grown with a higher $\mathrm{P}^{\mathrm{o}}{ }_{\mathrm{NH} 3}$, the number of $\mathrm{InN}$ islands decreased remarkably while their diameter increased. The crystalline quality of InN grown on the hexagonal islands with a high $\mathrm{P}_{\mathrm{NH} 3}^{\mathrm{N}}$ significantly improved with increasing growth time. A strong PL spectrum was observed only from InN layers grown with a high $\mathrm{P}^{\mathrm{o}}{ }_{\mathrm{NH} 3}$. It was thus revealed that an $\mathrm{NH}_{3}$ preflow and a high $\mathrm{P}^{\mathrm{o}}{ }_{\mathrm{NH}}$ are effective for producing $\mathrm{InN}$ with high crystalline quality and good optical and electrical properties.

\footnotetext{
*E-mail: rie0831@cc.tuat.ac.jp
} 


\section{Introduction}

InN is a promising material for high-speed and high-frequency electronic devices because it is predicted to have a small effective mass and a high electron drift velocity. In addition, long-wavelength light emitting devices can be fabricated due to its small band gap. However, there are many problems in growing InN, including a low growth rate, a poor thermal stability, and a lack of a suitable substrate. Thus, $\mathrm{InN}$ is one of the most difficult materials to grow epitaxially. To overcome these problems, we have investigated hydride vapor phase epitaxy (HVPE) of InN. HVPE is an attractive method since it has the potential to grow thick and high-quality InN layers at high growth rates. Our group has succeeded in preparing high-quality freestanding $\mathrm{GaN}^{1)}$ and $\mathrm{AlN}^{2)}$ substrates by HVPE. Based on the thermodynamic analysis, we used the reaction between $\mathrm{NH}_{3}$ gas and high-purity $\mathrm{InCl}_{3}$ gas generated by flowing $\mathrm{Cl}_{2}$ gas over In metal at the source zone in the HVPE system used for growing $\operatorname{InN}$. $^{3)}$ We found that single-crystal InN layers can be grown on a nitrided (0001) sapphire substrate and a freestanding \{0001\} GaN substrate by HVPE., ${ }^{3,4)}$ However, thicker and higher quality InN layers are required.

It has been widely reported that the crystalline quality of InN layers is strongly affected by the nucleation of islands during the initial growth stages and during the subsequent growth of the islands. In the case of InN grown by metalorganic vapor phase epitaxy (MOVPE), it has been reported that the crystalline quality of InN layers could be improved by changing the growth mode from three-dimensional to two-dimensional by varying the hydrogen partial pressure in the carrier gas and the growth temperature. ${ }^{5}$ ) In another study of InN growth by MOVPE, the crystalline quality was found to be significantly influenced by controlling the nucleation and the subsequent growth of 
islands by varying the growth temperature and the input $\mathrm{NH}_{3}$ /trimethylindium ratio. ${ }^{6}$ It is thus important to investigate the effect of the growth conditions on the nucleation of InN islands and the crystalline quality of the InN layer after subsequent growth.

In the present study, the effect of the source gas supply sequence prior to growth and the $\mathrm{NH}_{3}$ input partial pressure $\left(\mathrm{P}_{\mathrm{NH}}^{\mathrm{o}}\right)$ on the nucleation of $\mathrm{InN}$ islands on nitrided (0001) sapphire during the initial stages of HVPE was investigated. The crystalline quality of the InN layer after subsequent growth was also examined.

\section{Experimental Procedure}

InN was grown by means of an atmospheric-pressure HVPE system with a horizontal hot-wall quartz glass reactor. First, surface nitridation of a (0001) sapphire substrate was performed by $\mathrm{NH}_{3}$ gas with a partial pressure of 0.16 atm in flowing $\mathrm{H}_{2}$ gas at $1000{ }^{\circ} \mathrm{C}$ for $20 \mathrm{~min}$. The carrier gas was then changed to $\mathrm{N}_{2}$ and the substrate was cooled to the growth temperature of $500{ }^{\circ} \mathrm{C}$. Prior to the InN growth, a source gas was supplied to the surface of the nitrided sapphire substrate in one of the three source gas supply sequences: (a) $\mathrm{InCl}_{3}$ preflow for 5 min, (b) simultaneous supply of $\mathrm{InCl}_{3}$ and $\mathrm{NH}_{3}$, and (c) $\mathrm{NH}_{3}$ preflow for 5 min. The InN growth was subsequently performed at $500{ }^{\circ} \mathrm{C}$ for 5 to $60 \mathrm{~min}$ in flowing $\mathrm{N}_{2}$ by the reaction between $\mathrm{NH}_{3}$ and $\mathrm{InCl}_{3}$ gases. The $\mathrm{InCl}_{3}$ gas was generated by flowing $\mathrm{Cl}_{2}$ gas over $6 \mathrm{~N}$-grade In metal at the source zone,

which was held at $450{ }^{\circ} \mathrm{C}$. The input partial pressure of $\mathrm{Cl}_{2}$ was fixed at $3.0 \times 10^{-3} \mathrm{~atm}$, while the $\mathrm{NH}_{3}$ input partial pressure was varied from 0.030 to 0.38 atm.

X-ray diffraction (XRD), scanning electron microscopy (SEM), room-temperature Hall-effect measurements, and photoluminescence (PL) spectroscopy were used to analyze the grown InN. In the PL measurements, a $850 \mathrm{~nm}$ Ti:sapphire laser was used as 
the excitation source and a liquid-nitrogen-cooled InGaAs detector was used to monitor the emission.

\section{Results and Discussion}

The effect of the source gas supply sequence on nucleation of $\mathrm{InN}$ islands during the initial stages was examined. Prior to the InN growth, the source gas was flowed on the surface of the nitrided sapphire substrate in one of three source gas supply sequences: (a) $\mathrm{InCl}_{3}$ preflow for 5 min, (b) simultaneous supply of $\mathrm{InCl}_{3}$ and $\mathrm{NH}_{3}$, and (c) $\mathrm{NH}_{3}$ preflow with $\mathrm{P}_{\mathrm{NH}}^{\mathrm{o}}$ of $0.030 \mathrm{~atm}$ for $5 \mathrm{~min}$. Subsequently, all samples were grown with $\mathrm{P}^{\mathrm{o}}{ }_{\mathrm{NH} 3}$ of $0.030 \mathrm{~atm}$ for $5 \mathrm{~min}$. The surface SEM micrographs in Fig. 1 reveal that the surface morphology varied significantly for the three source gas supply sequences. When InN was grown with $\mathrm{InCl}_{3}$ preflow or simultaneous supply, several packed $\mathrm{InN}$ islands formed on the surface of the nitrided sapphire. In contrast, separated $\mathrm{InN}$ islands with hexagonal facets were observed, when $\mathrm{NH}_{3}$ was flowed prior to growth. XRD $\theta-2 \theta$ measurements were also performed for the same InN samples, as shown in Fig. 2. This figure shows that a (0002) InN diffraction peak and the sapphire substrate peak were observed for all samples. However, a $\left(10^{-}, 11\right)$ InN peak was also observed for $\mathrm{InN}$ grown with $\mathrm{InCl}_{3}$ preflow. Furthermore, the six-fold symmetry was confirmed by $\varphi$-scans X-ray rocking curves (XRCs) of $\left(10^{-}, 12\right) \mathrm{InN}$ from samples (b) and (c) (not shown here). Thus, single-crystal $\mathrm{InN}$ can be grown with simultaneous supply of $\mathrm{InCl}_{3}$ and $\mathrm{NH}_{3}$, or $\mathrm{NH}_{3}$ preflow prior to the InN growth. $\mathrm{NH}_{3}$ preflow is expected to be particularly effective for producing high-quality $\mathrm{InN}$ since the density of dislocations caused by coalescence of the islands is thought to decrease during the subsequent growth due to the low island density on the surface. 
To clarify the detailed effects of $\mathrm{NH}_{3}$ gas flow on the nitrided surface on the nucleation of InN islands during the initial stages, nucleation was examined for various values of $\mathrm{P}_{\mathrm{NH} 3}^{\mathrm{o}}$. Figure 3 shows surface SEM micrographs of $\mathrm{InN}$ grown with $\mathrm{P}^{\mathrm{o}}{ }_{\mathrm{NH} 3}$ between 0.030 and 0.38 atm at $500{ }^{\circ} \mathrm{C}$ for 10 min with 5 min $\mathrm{NH}_{3}$ preflow with the same value of $\mathrm{P}^{\mathrm{o}}{ }_{\mathrm{NH} 3}$ as during growth. The micrographs reveal that the number of $\mathrm{InN}$ islands decreases, while the island diameter increases with increasing $\mathrm{P}^{\mathrm{o}}{ }_{\mathrm{NH} 3}$. When $\mathrm{InN}$ was grown with a high $\mathrm{P}^{\mathrm{o}}{ }_{\mathrm{NH} 3}(0.38 \mathrm{~atm})$, sharp hexagonal $\mathrm{InN}$ pyramids surrounded by $\left[10^{-}, 11\right]$ facets were observed on the nitrided sapphire substrate. These results may be due to the sticking coefficient of the In source varying with the top surfaces of nitrided sapphire substrates produced by various $\mathrm{P}^{\mathrm{o}} \mathrm{NH3}$ because the surface of a AlN layer ${ }^{7)}$ or an amorphous layer consisting of $\mathrm{AlN}_{X} \mathrm{O}_{1-x}{ }^{8)}$ that forms after nitridation of sapphire varies with $\mathrm{P}^{\mathrm{O}}{ }_{\mathrm{NH} 3}$, as found by a first-principles study. ${ }^{9)}$ Furthermore, the color of the samples changed from reddish to black with increasing $\mathrm{P}^{\mathrm{o}}{ }_{\mathrm{NH}}$. This is thought to be caused by a greater incorporation of impurities in $\mathrm{InN}$ grown with a lower $\mathrm{P}^{\mathrm{o}} \mathrm{NH3}$ during the initial stages due to the larger number of islands on the surface. Thus, both $\mathrm{NH}_{3}$ preflow prior to InN growth and a high $\mathrm{P}^{\mathrm{o}}{ }_{\mathrm{NH} 3}$ appear to be effective in reducing the impurity incorporation during the initial stages, in reducing the density of dislocations caused by coalescence of islands, and in reducing the dislocation density by lateral $\mathrm{InN}$ growth on the hexagonal islands. ${ }^{5,10)}$

To investigate the subsequent lateral InN growth, the effect of growth time on the evolution of InN islands was examined. Figure 4 shows surface SEM micrographs that indicate the growth time dependence of the InN growth with $\mathrm{P}^{\mathrm{o}}{ }_{\mathrm{NH} 3}$ of 0.38 and 0.030 atm. It shows that $\mathrm{InN}$ tends to grow more laterally (i.e., perpendicular to the $c$-axis) with increasing growth time. After $1 \mathrm{~h}$ growth, both surfaces of the lateral grown InN 
layers were relatively flat and the $\mathrm{InN}$ grown with $\mathrm{P}^{\mathrm{o}}{ }_{\mathrm{NH} 3}$ of 0.38 and $0.030 \mathrm{~atm}$ had thicknesses of 860 and $780 \mathrm{~nm}$, respectively. Additionally, the structural quality of InN as a function of growth time was evaluated. Figure 5 shows the growth time dependence of the full-width at half-maximum (FWHM) values of XRCs for (0002) InN diffraction corresponding to the tilt distribution and $\left(10^{-}, 10\right) \mathrm{InN}$ diffraction corresponding to the twist distribution. It shows that the twist distribution was drastically improved with no deterioration in the tilt distribution with increasing growth time. This tendency agrees well with previous reports in which InN films were regrown on micro-facetted N-polar InN templates by radio-frequency molecular beam epitaxy. ${ }^{10)}$ This result suggests that the threading dislocation density of the $\mathrm{InN}$ layer decreases due to bending of the threading dislocations, which is thought to occur during lateral growth. In particular, InN grown with a high $\mathrm{P}^{\mathrm{o}}{ }_{\mathrm{NH}}(0.38 \mathrm{~atm})$ for $1 \mathrm{~h}$ exhibited smaller FWHM values of 20.2 and 53.4 arcmin for tilt and twist distributions respectively than those InN structures grown with a low $\mathrm{P}^{\mathrm{o}}{ }_{\mathrm{NH} 3}(0.030 \mathrm{~atm})$ (47.4 and 96.0 arcmin, respectively). This difference suggests that the number of threading dislocations induced by coalescence of the islands decreased with increasing $\mathrm{P}^{\mathrm{o}}{ }_{\mathrm{NH} 3}$ because $\mathrm{InN}$ grown with the high $\mathrm{P}^{\mathrm{o}}{ }_{\mathrm{NH} 3}$ (0.38 atm) has a lower density of InN islands in the initial stages. In addition, when InN was grown with a high $\mathrm{P}^{\mathrm{o}}{ }_{\mathrm{NH}}(0.38 \mathrm{~atm})$, InN seems to grow significantly in the lateral directions (i.e., perpendicular to the $c$-axis) during growth. Hence, a high $\mathrm{P}_{\mathrm{NH} 3}^{\mathrm{o}}$ is effective for growing InN with a high structural quality on nitrided sapphire substrates.

To investigate the influence of $\mathrm{P}^{\mathrm{o}} \mathrm{NH3}$ on the incorporation of impurities in the layers, the $a$ - and $c$-axis lattice constants were determined from asymmetric reciprocal space maps (RSMs) around $\left(11^{-}, 2^{-}, 12\right)$ sapphire and $\left(10^{-}, 1^{-}, 5\right)$ InN points, because the impurity incorporation in an InN layer has been reported to increase the lattice constants 
of InN. ${ }^{11,12)}$ The obtained RSMs reveal that the lattice constants of $a=3.542 \AA$ and $c=5.711 \AA$ for $\mathrm{InN}$ grown with a high $\mathrm{P}^{\mathrm{o}}{ }_{\mathrm{NH} 3}(0.38 \mathrm{~atm})$ for $1 \mathrm{~h}$ are slightly smaller than those of $a=3.547 \AA$ and $c=5.711 \AA$ for $\operatorname{InN}$ grown with a low $\mathrm{P}^{\mathrm{o}}{ }_{\mathrm{NH} 3}(0.030 \mathrm{~atm})$, whereas the $c / a$ ratio is similar, about 1.61 . However, both these values are larger than those reported for high-quality InN. ${ }^{13)}$ It is thus thought that large amounts of impurities such as oxygen, hydrogen, and/or chlorine were incorporated into both layers, although InN grown with a high $\mathrm{P}^{0}{ }_{\mathrm{NH} 3}(0.38 \mathrm{~atm})$ had a slightly lower incorporation of impurities. Hall-effect measurements at room temperature were also performed. The carrier concentrations in the layers grown with $\mathrm{P}^{\mathrm{o}}{ }_{\mathrm{NH} 3}$ of 0.38 and 0.030 atm were $6.6 \times 10^{20}$ and $9.1 \times 10^{20} \mathrm{~cm}^{-3}$, respectively, with n-type conductivity and their mobilities were 56 and $33 \mathrm{~cm}^{2} \mathrm{~V}^{-1} \mathrm{~s}^{-1}$, respectively. The relationship between the lattice parameters and the carrier concentrations implies that the greater electron concentrations were caused by the greater incorporation of impurities with decreasing $\mathrm{P}^{\mathrm{O}}{ }_{\mathrm{NH} 3}$.

Finally, the dependence of the optical properties on $\mathrm{P}^{\mathrm{o}}{ }_{\mathrm{NH} 3}$ was examined by performing PL measurements. PL spectra at $5 \mathrm{~K}$ for $\mathrm{InN}$ layers grown with different $\mathrm{P}^{\mathrm{o}}{ }_{\mathrm{NH} 3}$ were obtained, as shown in Fig. 6. InN grown with a high $\mathrm{P}^{\mathrm{o}}{ }_{\mathrm{NH} 3}(0.38 \mathrm{~atm})$ had a much higher integrated PL intensity than InN grown with a low $\mathrm{P}^{\mathrm{o}}{ }_{\mathrm{NH} 3}(0.030 \mathrm{~atm})$. This may be due to an improved twist distribution. Muto et al. reported that edge dislocations, which are related to the twist distribution, act as non-radiative recombination centers in InN. ${ }^{10)}$ However, further investigation is required to confirm this. Moreover, the peak photon energy decreased from 0.89 to $0.76 \mathrm{eV}$ with increasing $\mathrm{P}^{\mathrm{o}}{ }_{\mathrm{NH} 3}$ and an asymmetric PL spectrum with low-energy tails was clearly obtained. Previous studies found that the peak photon energy increases and the spectrum became more asymmetric and 
broadened with increasing electron concentration in the layer. ${ }^{14,15)}$ These findings agree well with those obtained by Hall-effect and PL measurements in the present study.

\section{Conclusions}

We investigated the effect of the source gas supply sequence prior to growth and the $\mathrm{NH}_{3}$ input partial pressure $\left(\mathrm{P}^{\mathrm{o}}{ }_{\mathrm{NH}}\right)$ during $\mathrm{HVPE}$ growth on the nucleation of $\mathrm{InN}$ islands on nitrided (0001) sapphire and the crystalline quality of the InN layer after subsequent growth. When InN was grown with $\mathrm{NH}_{3}$ preflow, single-crystal hexagonal InN islands formed on the nitrided surface. Further, when InN was grown with a high $\mathrm{P}^{\mathrm{o}}{ }_{\mathrm{NH}}$ with $\mathrm{NH}_{3}$ preflow, the number of $\mathrm{InN}$ islands decreased remarkably and the islands diameters increased. In particular, when InN was grown with a high $\mathrm{P}^{\mathrm{o}}{ }_{\mathrm{NH} 3}(0.38$ atm), sharp hexagonal InN pyramids surrounded by $\left[10^{-}, 11\right]$ facets were formed. The crystalline quality of $\mathrm{InN}$ grown on the hexagonal islands with a high $\mathrm{P}^{\mathrm{o}}{ }_{\mathrm{NH}}$ significantly improved with increasing growth time. In addition, the InN layer grown with a high $\mathrm{P}^{\mathrm{o}}{ }_{\mathrm{NH} 3}$ had a slightly lower impurity concentration. A strong PL spectrum was observed only from the InN layer grown with a high $\mathrm{P}^{\circ}{ }_{\mathrm{NH}}$. Therefore, when $\mathrm{InN}$ was grown on nitrided (0001) sapphire by HVPE, $\mathrm{NH}_{3}$ preflow prior to growth and a high $\mathrm{P}^{\mathrm{o}}{ }_{\mathrm{NH} 3}$ are quite effective for producing $\mathrm{InN}$ with high crystalline quality and good optical and electrical properties.

\section{Acknowledgments}

This work was partly supported in part by a Grant-in-Aid for Young Scientist (B) No. 2376006 from the Ministry of Education, Culture, Sports, Science and Technology of 
Japan, and by the International Training Program conducted by Tokyo University of Agriculture and Technology and the Japan Society for the Promotion of Science. 
1) Y. Kumagai, F. Satoh, R. Togashi, H. Murakami, K. Takemoto, J. Iihara, K. Yamaguchi, and A. Koukitu: J. Cryst. Growth 296 (2006) 11.

2) Y. Kumagai, Y. Kubota, T. Nagashima, T. Kinoshita, R. Dalmau, R. Schlesser, B. Moody, J. Xie, H. Murakami, A. Koukitu, and Z. Sitar: Appl. Phys. Express 5 (2012) 055504.

3) Y. Kumagai, J. Kikuchi, Y. Nishizawa, H. Murakami, and A. Koukitu: J. Cryst. Growth 300 (2007) 57.

4) R. Togashi, H. Murakami, Y. Kumagai, and A. Koukitu: J. Cryst. Growth 312 (2010) 651.

5) H. Murakami, H. -C. Cho, Y. Kumagai, and A. Koukitu: J. Cryst. Growth 310 (2008) 4954.

6) H. Wang, D. S. Jiang, J. J. Zhu, D. G. Zhao, Z. S. Liu, Y. T. Wang, S. M. Zhang, and H. Yang: Semicond. Sci. Technol. 24 (2009) 055001.

7) A. Yamamoto, M. Tsujino, M. Ohkubo, and A. Hashimoto: J. Cryst. Growth 137 (1994) 415.

8) K. Uchida, A. Watanabe, F. Yano, M. Kouguchi, T. Tanaka, and S. Minagawa: J. Appl. Phys. 79 (1996) 3487.

9) H. Suzuki, R. Togashi, H. Murakami, Y. Kumagai, and A. Koukitu: Jpn. J. Appl. Phys. 46 (2007) 5112.

10) D. Muto, H. Naoi, T. Araki, S. Kitagawa, M. Kurouchi, H. Na, and Y. Nanishi: Phys. Status Solidi A 203 (2006) 1691.

11) A. G. Bhuiyan, K. Sugita, K. Kasashima, A. Hashimoto, A. Yamamoto, and V. Y. Davydov: Appl. Phys. Lett. 83 (2003) 4788. 
12) Y. Kumagai, H. Adachi, A. Otake, Y. Higashikawa, R. Togashi, Y. Kumagai, and A. Koukitu: Phys. Status Solidi C 7 (2010) 2022.

13) V. Y. Davydov, A. A. Klochikhin, V. V. Emtsev, D. A. Kurdyukov, S. V. Ivanov, V. A. Vekshin, F. Bechstedt, J. Furthmüller, J. Aderhold, J. Graul, A. V. Mudryi, H. Harima, A. Hashimoto, A. Yamamoto, and E. E. Haller: Phys. Status Solidi B 234 (2002) 787.

14) B. Arnaudov, T. Paskova, P.P. Paskov, B. Magnusson, E. Valcheva, B. Monemar, H. Lu, W.J. Schaff, H. Amano, and I. Akasaki: Phys. Rev. B 69 (2004) 115216.

15) S. P. Fu, T. T. Chen, and Y. F. Chen: Semicond. Sci. Technol. 21 (2006) 244. 
Fig. 1 Surface SEM micrographs of InN grown with one of three source gas supply sequences: (a) $\mathrm{InCl}_{3}$ preflow for 5 min prior to growth, (b) simultaneous supply of $\mathrm{InCl}_{3}$ and $\mathrm{NH}_{3}$, and (c) $\mathrm{NH}_{3}$ preflow for 5 min prior to growth. Growth was performed with a $\mathrm{NH}_{3}$ input partial pressure of 0.030 atm for $5 \mathrm{~min}$.

Fig. 2 XRD $\theta-2 \theta$ profiles of InN grown with one of three source gas supply sequences: (a) $\mathrm{InCl}_{3}$ preflow for 5 min prior to growth, (b) simultaneous supply of $\mathrm{InCl}_{3}$ and $\mathrm{NH}_{3}$, and (c) $\mathrm{NH}_{3}$ preflow for 5 min prior to growth. Growth was performed with a $\mathrm{NH}_{3}$ input partial pressure of $0.030 \mathrm{~atm}$ for $5 \mathrm{~min}$.

Fig. 3 Surface SEM micrographs of InN during the initial stages of growth with $\mathrm{NH}_{3}$ input partial pressures of (a) 0.030 , (b) 0.15 , and (c) 0.38 atm. Growth was performed at $500^{\circ} \mathrm{C}$ for 10 min with 5 min $\mathrm{NH}_{3}$ preflow prior to growth.

Fig. 4 Surface SEM micrographs showing the growth time dependence of InN growth at $500{ }^{\circ} \mathrm{C}$ on the $\mathrm{NH}_{3}$ input partial pressure; (a-d) 0.38 and (e-h) 0.030 atm.

Fig. 5 FWHM values of XRCs for $(0002)$ and $\left(10^{-}, 10\right)$ InN diffraction as a function of the growth time: InN grown with $\mathrm{NH}_{3}$ input partial pressures of 0.38 (open circles and squares) and 0.030 atm (solid circles and squares).

Fig. $6 \mathrm{PL}$ spectra measured at $5 \mathrm{~K}$ of $\mathrm{InN}$ layers grown at $500{ }^{\circ} \mathrm{C}$ for $1 \mathrm{~h}$ with $\mathrm{NH}_{3}$ input partial pressures of 0.38 and $0.030 \mathrm{~atm}$, respectively. 

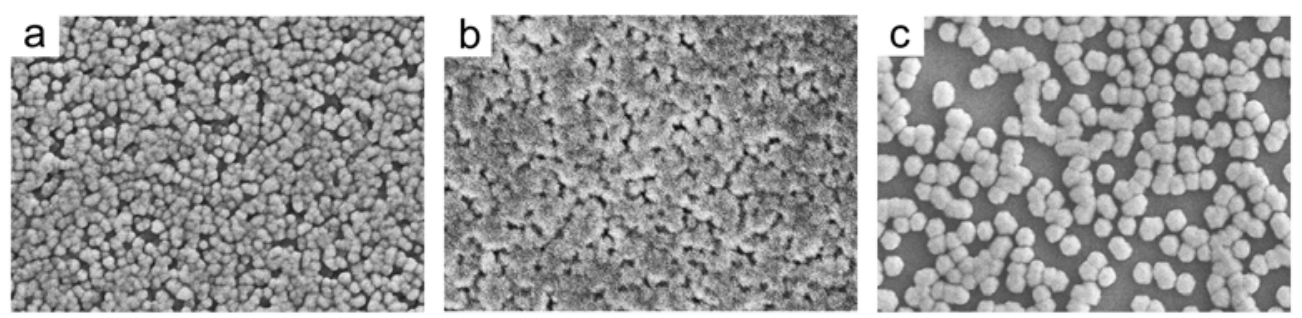

$1 \mu \mathrm{m}$

Fig. 1. R. Togashi et al. 


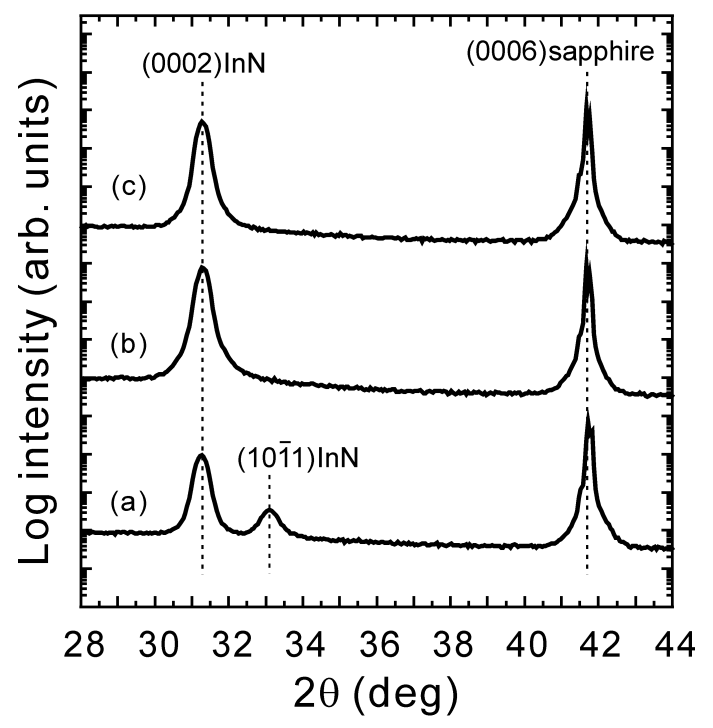

Fig. 2. R. Togashi et al. 


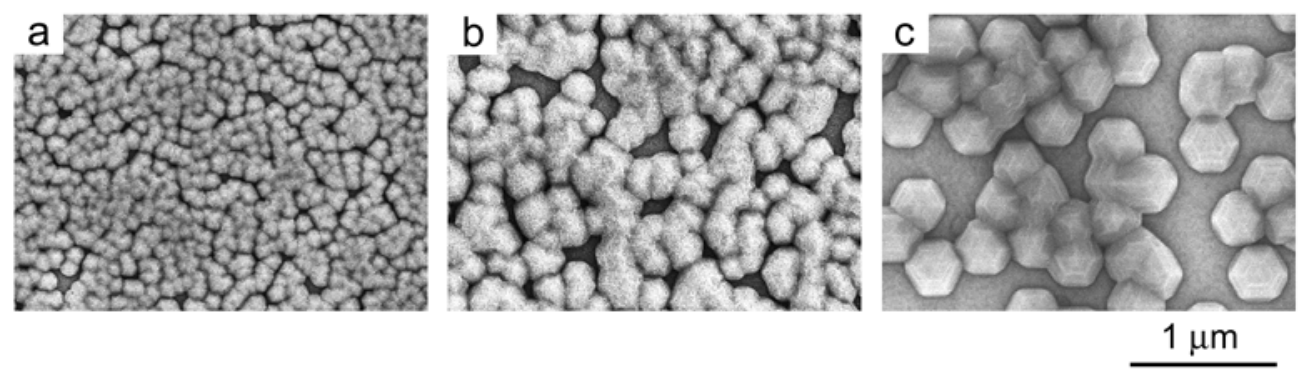

Fig. 3. R. Togashi et al. 


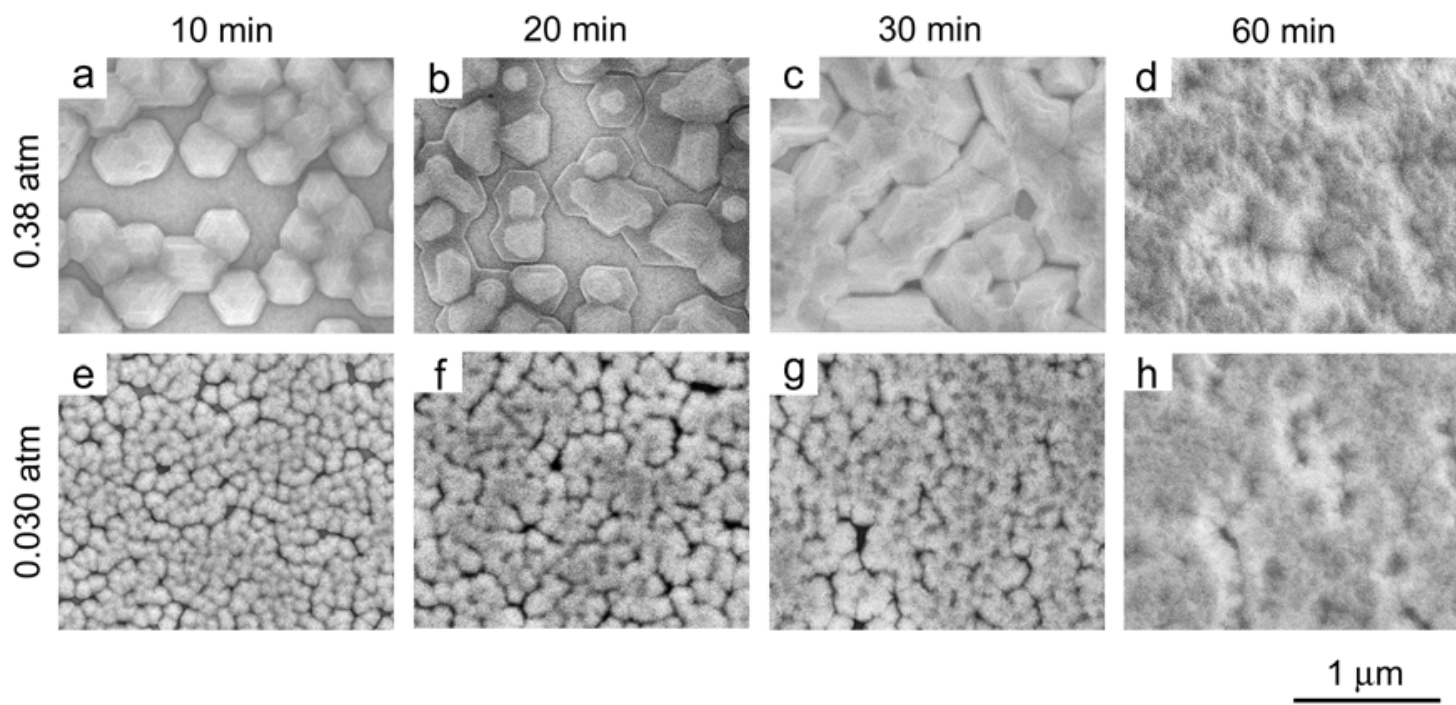

Fig. 4. R. Togashi et al. 


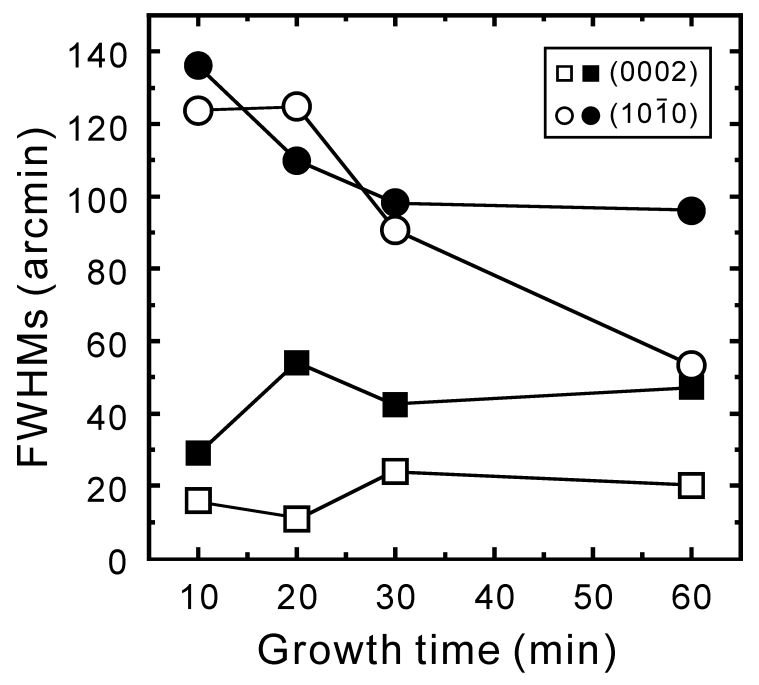

Fig. 5. R. Togashi et al. 


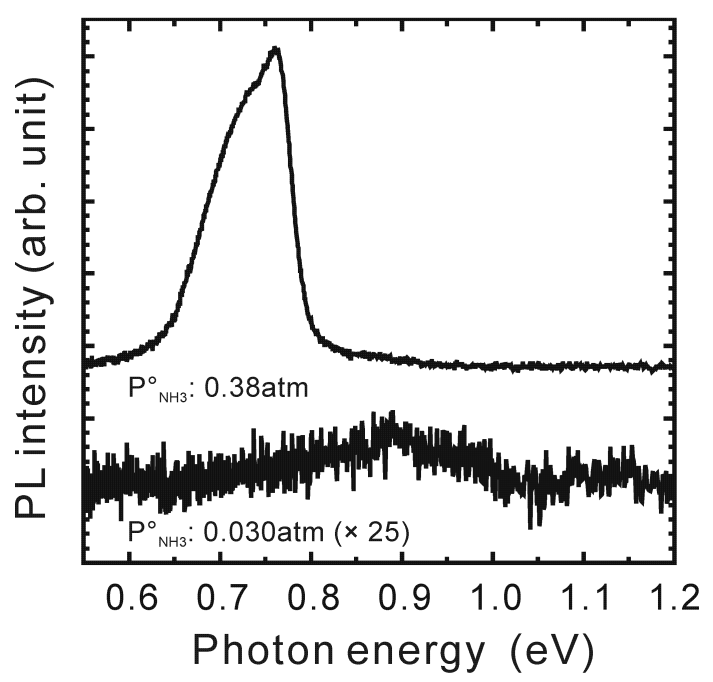

Fig. 6. R. Togashi et al. 